\title{
Microparticle Enzyme Immunoassay
}

National Cancer Institute

\section{Source}

National Cancer Institute. Microparticle Enzyme Immunoassay. NCI Thesaurus. Code C111252.

A type of enzyme immunoassay that uses antigen-coated microparticles as a substrate for antibody binding. 